\title{
El fenómeno Malpaís: signos identitarios del costarricense en sus canciones-poemas
}

\author{
Marlen Calvo Oviedo \\ Escuela de Estudios Generales \\ Universidad de Costa Rica \\ Maestría en Diplomacia del \\ Instituto Manuel María Peralta
}

\begin{abstract}
Resumen
Malpaís es un grupo de música muy particular, pues con sus canciones y los signos que en ellas se expresan, ha logrado calar hondo en la reafirmación del imaginario del ser costarricense, desde la ciudad hasta la llanura. En esos contextos, citadinos o pamperos, el costarricense se dobla, se desdobla y se reconoce en elementos que están dichos, cantados, acompasados. Es nuestra intención ir descubriendo en las letras de algunas canciones escritas y musicalizadas por Malpais, esos elementos sígnicos que le dieron a los y las costarricenses ese paradigma identitario tan intenso.
\end{abstract}

Palabras claves: Malpaís, canción-poema, signo, identidad costarricense

\begin{abstract}
Malpais is a band with a very particular kind of music that because of their songs, and the characteristics shown in them, has managed to penetrate deeply in the reaffirmation of the imaginary of the Costa Rican being, from the city to the plain. In those contexts, city residents as well as country people, Costa Ricans fold and unfold themselves and are also recognized within elements, ingredients that are said, sung, musicalized. It is our goal to discover in some songs, lyrics, and music done by Malpais, those signical elements that have given such an intense identity to Costa Rican people.
\end{abstract}

Key words: Malpais, song-poem, sign, Costa Rican identity 
Aunque ya no soy nada, como ves, polvo soy porque polvo siempre fui, pero el polvo que soy huele a jazmín.

\section{Malpaís, el grupo}

$\mathrm{E}$ s una banda musical costarricense, integrada, inicialmente, por seis músicos de gran trayectoria, dos de ellos hermanos, Fidel y Jaime Gamboa, el primero determinado como creador del grupo. Nace en 1999 y dan sus primeros conciertos en 2001. Desde sus inicios caló hondo en los y las costarricenses, como se afirma en su página web: "El universo de Malpaís, recogido en las canciones de Fidel Gamboa, y en las letras de su hermano Jaime, ya han pasado a formar parte del imaginario colectivo de los "ticos", más allá de si tienen 15 u 80 años".

En el auge de su carrera musical y después de varios premios, pierden a su creador en agosto de 2011 y deciden retirarse, pero la insistencia del público los hace regresar. Ahora con una voz nueva, una joven que fue su corista en muchos momentos, Daniela Rodríguez, el grupo continúa con cinco de sus integrantes originales: Jaime Gamboa, Iván Rodríguez, Manuel Obregón, Carlos Vargas (Tapao) y Gilberto Jarquín.

Y aunque no es parte del grupo, algunas de sus canciones son escritas por otro de los hermanos Gamboa, Héctor, y de vez en cuando Max Goldenberg, tío de los hermanos Gamboa por línea materna y cantautor nicoyano, quien también ha participado con sus canciones en los conciertos; y para finalizar con la imagen de familia, Iván y Daniela Rodríguez son padre e hija.

Como podemos apreciar, Malpaís, además de su música, le ofrece al público otros elementos necesarios para la identidad y es la pertenencia a la familia, al grupo, a los amigos, quizá a eso se deba que los rodeen tantos jóvenes costarricenses que se identifican con su música; ellos mismos lo expresan en su página web cuando afirman:

Durante todo el 2007 nuestro principal público han sido los estudiantes de secundaria, quienes se han acercado a nosotros sin duda buscando una identidad nacional que a menudo sienten opacada por la gran cantidad de imágenes, música y modelos culturales norteamericanos. Este acercamiento nos hace sentir una gran confianza en el futuro de la música costarricense con identidad. Ahora hay un enorme público, un nuevo público, que con gran entusiasmo está volviendo sus ojos y oídos hacia lo propio, y esto sin duda beneficiará a toda la producción musical y artística del país.

Finalmente, llevan el nombre de unas playas costarricenses ubicadas en el océano Pacífico, específicamente en la provincia de Puntarenas, en la Península de Nicoya, referente de muchos de los temas de este grupo musical; de su nombre ellos han dicho: 
Al final de la península de Nicoya, más allá de Cabo Blanco y del último camino, está el refugio de los desterrados, el potrero inhóspito sin fin, la playa de basalto donde no sabemos si vamos o si volvemos. La playa de Malpaís, el Paraíso.

Un mal nombre para un lugar tan bello. Una contradicción. Quizá tan contradictorio como el nombre de la propia Costa Rica, que durante siglos fue el rincón más pobre del continente. (www.grupomalpais.com)

\section{Estudio}

Una de las partes esenciales de los textos literarios, en cuanto a la producción del sentido, es la parte simbólica. Los símbolos son esas unidades mínimas que tienen una gran capacidad de carácter significativo, que se mueven de una época a otra y de un contexto a otro, subsistiendo extraordinariamente estables a lo largo de la historia de las culturas, y a la vez ajustándose a una gran y diversa posibilidad de contextos semióticos. El ser humano es un ser simbólico, o como diría Ernst Cassirer (1874-1945), un animal simbólico.

Conocemos desde Lotman (2003) que el símbolo posee una doble naturaleza ya que, por un lado, se sustenta en su esencia invariable por medio de la recurrencia y, por otro lado, se correlaciona rápidamente con el contexto cultural, que a su vez se transforma bajo su influencia y es transformado por ésta. El símbolo no pertenece a un corte sincrónico, sino que va atravesando las distintas culturas desde el pasado hacia el futuro por lo que la memoria del símbolo es mucho más antigua que cualquier nuevo sentido en otro contexto, y ese sentido arcaico es muy estable, ya que está cargado de otros agentes culturales.

Existen símbolos sumamente importantes a lo largo de diferentes culturas y de grupos humanos en particular, así: el árbol, el fuego, el cielo, la tierra, el amor, las aves, el vuelo, y tantos otros que corresponden a una estructura mental humana, independientemente del grupo cultural al que se pertenezca. Gran cantidad de ellos se encuentran en las canciones-poemas de Malpaís, inmersos además en un contexto muy costarricense, absolutamente reconocibles y con una gran carga emotiva de ser tico (costarricense); son frases como:

Guanacaste ya no está. /Ya no me lo canta el viento. / Es que tengo que buscar/ más al norte del recuerdo/.

Y vi la pampa árida temblar, / oí el ronco quijongo y la ceniza/sudando guaro, estúpido y brutal/ en aquella provincia, que fue mía.

Y nos preguntamos aquí, qué costarricense que ame estas tierras no podrá sentirse incluido en ese texto, e incluso en este otro:

Solo quería volver /a mirar el mar /que aquella noche miramos /...

Sólo quería volver/ a besar la sal/ que había en tu cuerpo mojado /...

Para encontrar la inocencia/ perdida en el tímido azul / de las olas/...

Para bailar en la playa/ un bolero canalla/para sentir tu piel en mi piel... 
El amor, la conquista, la pérdida de la inocencia, el recuento de la vida, temas que tocan lo humano, y el paisaje del mar como marco, las playas costarricenses, el mar salado y cálido. La palabra, el enunciado, materia viva en lo profundo del ser, la transmisión de una serie de símbolos desde una canción-poema, como lo plantea Manuel Alvar (1990), señal + carga afectiva= signo (62).

El artista, el escritor, es capaz de leer los signos de su época y mezclarlos con los signos que Lotman (2003) llama elementales, es decir, aquellos que le son comunes a gran parte de la cultura humana, y crear así un enunciado en forma de canción-poema que pone de manifiesto muchos de los problemas que son comunes a los y las costarricenses. En este caso, Lotman (1978) afirma que el texto es la experiencia del arte, es decir, "lo dado real estético" (134) y que las propiedades del mensaje se transforman en propiedades del código (135). Es decir, el mensaje de cada obra de arte será el resultado del código que el artista ha escogido para presentar su obra.

Malpaís hace que sus canciones-poemas evoquen identidad en sus escuchas, emotividad de su ser costarricense, humano, latinoamericano; y combina, interesantemente, dos lenguajes: el literario y el musical, es decir, ese es el código estético que escogieron para cifrar su mensaje, su arte. Dice Lotman que en el arte verbal es imposible separar el sonido del sentido (1978: 154), convertidos ambos en un todo global.

Aunque en este trabajo nos ocupemos en revisar lo literario de las canciones-poemas de este grupo musical, sabemos que aprehender a Malpais implica también la música que acompaña sus letras. Sabemos que el artista puede tener una sensibilidad inusual a la belleza, a las estructuras naturales o, como lo diría David Bohm (2001), a la belleza de las formas y estructuras naturales (66); hay en las letras de este grupo musical una recurrencia sensible a todo lo natural que lo rodea, así como una fusión de mundos oscuros y claros, naturales y culturales en la que todo posee valor en un mismo plano; nada es más, nada es menos.

Decía Fidel Gamboa que para él era más sencillo pensar en una melodía que en una letra, pero muchas veces las palabras alimentan la música (La Nación, 2006), lo cual quizá explique ese fenómeno del grupo Malpaís en su capacidad de mover fibras en jóvenes y viejos, así como en los distintos géneros humanos y hacerlos cantar en una sola voz que se identifica con y en las canciones. Sonido y discurso fundidos en un todo como dice Bohm (2006) parafrasenado a Leonardo da Vinci: "El movimiento modela las formas. La estructura da orden al movimiento" (129), los movimientos musicales y la estructura discursiva se unen para modelar un mensaje profundo e identitario.

El auténtico banquete intelectual requiere un chef que sepa mezclar, combinar y sazonar adecuadamente un amplio surtido de ingredientes mentales (RootBernstein, 2000:15). Gamboa señalaba que esa identificación de los costarricenses con la música de Malpaís posiblemente se debía a que ellos decidieron contar historias: "creo que tocamos un filón que tenían los ticos muy adentro y empezó a salir" (La Nación, 2006), esas historias liberaron sentimientos, arraigos, amores, poemas que implicaron para los escuchas emociones intensas que surgían del grupo hacia su público en una aproximación casi pictórica, reforzada con sonidos, 
gestos, miradas y las figuras en el escenario, lo cual pasaba casi intacto a sus producciones discográficas y a la cultura nacional:

El canto y la existencia de canciones, son fenómenos presentes en la vida social desde tiempos remotos. Es característico de estas pequeñas formas de la lírica, el comportarse como objetos animados que establecen recorridos insospechados tanto en la geografía como en la historia. La canción es ala y ave; es movimiento sonoro en despliegue por el espacio, es palabra retenida por la memoria y es también gesto y palpitación. Esas cualidades de la canción la hacen un material dúctil, capaz de generar intercambios culturales. (Lara Romero, 2004: 82)

Podemos comprender entonces esa relación en la que todas las personas seguidoras del grupo se identifican con él, guardan, reproducen y cantan su música porque ellos, los costarricenses, se encuentran allí. Se conforma una historia textual que produce un imaginario que a su vez se asienta en esa colectividad. Es decir, el texto es pensado como experiencia de arte, lo dado real estético (Lotman, 1978: 134) que constituye un todo estructural (secundario) que signa una serie de elementos que le otorgan ese carácter identitario al que nos referimos. Veamos como ejemplo la canción Como un pájaro, letra de Fidel Gamboa:

Como un pájaro...

Como un pájaro...en la mañana

Como un pájaro...en la mañana

Que sacude el viento...

Voy llegando...

Voy llegando a la distancia...

Como un pájaro...

Como la primera luz del mes de enero.

Como un árbol

Como un árbol apretado contra el cielo...

Como un árbol apretado contra el cielo...

Más azul, de todos los cielos (...)

Los malinches florecidos, aquel fuego (...)

Como lluvia

Como lluvia...pasajera (...)

Los sustantivos que componen el discurso textual son simples, se repiten e imprimen fuerza en las imágenes, a la vez que le otorgan movimiento: el pájaro, la mañana, el viento, el árbol, el cielo. Todos estos sustantivos se relacionan con espacios abiertos, lo que imprime además en el texto una sensación inherente al ser costarricense, la libertad. 
El uso del símil le permite a la voz emisora compararse, en su deseo de llegar con los cuatro elementos esenciales: tierra, aire (viento), agua y fuego, todos referidos a él, a su pasión por el regreso, el regreso a la primitiva esencia de las cosas, como lo afirma la voz en los siguientes versos: /Sé que a veces miro para atrás/ Pero es para saber de dónde vengo/, develando así, el sentido oculto en las palabras lo que nos integra como humanidad/ lo eterno se vuelve actual y de nuevo nos re-conocemos.

No se trata de cosas nuevas, sino de eternos humanos, mezclados y dichos desde una actualidad contextual; es el árbol que dentro de otras tantas cosas también representa el retorno al ser, estado edénico y que en muchas tradiciones se le ha llamado el árbol de la vida, también tiene un papel central en este texto y en muchos otros textos producidos por Malpais.

Como signo y símbolo, el árbol lo encontramos en varias formas en la canción-poema que analizamos: Como un árbol... apretado contra el cielo/Más azul de todos los cielos.../Deshojado/ Deshojado en cada beso/ Como un árbol/...Los malinches florecidos, aquel fuego/Como un árbol.../como un árbol sacudido por el viento.../. Como podría afirmarse desde Chevalier (1986), el árbol es el universo vivo en constante regeneración. También simboliza el carácter cíclico de la evolución cósmica: muerte y resurrección. El árbol pone en comunicación los tres niveles del cosmos: el subterráneo por sus raíces hurgando en las profundidades donde se hunden; la superficie de la tierra, por su tronco y sus primeras ramas; las alturas por sus ramas superiores y su cima, atraídas por la luz del cielo.

El árbol se manifiesta en la canción-poema en distintos aspectos relacionados con la tradición simbólica de éste, por ejemplo en comunicación directa con el cielo, /...Un árbol apretado contra el cielo.../ Como muerte y resurrección /un árbol deshojado/ y /malinches florecidos/, y el árbol como eje central sin más características que ser sacudido por el viento: raíz, tronco y ramas (los tres niveles del cosmos).

Es interesante detenerse un momento aquí y observar cómo la voz se integra por medio de todos estos elementos al paisaje descrito, sobre todo con el uso del símil. Vemos también cómo todos los distintos sustantivos se integren para darnos un paisaje en movimiento a partir de palabras que a su vez constituyen tradiciones humanas ancestrales con paisajes contemporáneos y reconocibles para todo ser costarricense.

El mensaje característico de cada canción y su musicalización es el resultado del código propio que el creador ha dispuesto en su momento creativo, pero difícilmente el producto esté deslindado del contexto en el que surge; no obstante, el creador estético y sus códigos combinarán de tal manera los elementos, lingüísticos y no, que el mensaje resultante será totalmente original y nuevo, como diría Lotman (1978: 135) "las propiedades del mensaje se transforman en propiedades del código".

El yo es el eje central de la persona del poema-canción; cada experiencia dicha se plantea desde una voz que vive y expresa en sí misma todas las sensaciones descritas. Esa voz es incondicional ante la subjetividad de lo referido, con lo que podríamos afirmar que orienta la respuesta del otro, del que escucha y 
construye su propio texto desde las imágenes y sensaciones ofrecidas, por ejemplo del contexto. Ese yo que le ofrece a ese otro ese algo que le falta.

Lacan (2008) establece una doble función para la enunciación, ser una demanda en relación con el tú: "me demando lo que tú deseas (...) lo que te falta, ligado al hecho que estoy sujetado a ti" (79). En el caso que nos ocupa, los signos en relación con el contexto y lo humano que la voz expresa, en primera persona, nos presentan situaciones de libertad rodeadas de paisajes invadidos de imágenes conocidas por los y las costarricenses, pertenecientes al inicio del verano, cuando los árboles botan sus hojas, el cielo está azul, las plantas en flor (malinches), el polvo es rey de los caminos (época seca) y tantos otros que se expresan desde un yo para llegar a un tú que se a su vez se completa; así, el yo y su enunciado se acercan y complementan, como sucede en la lírica.

Stephen Spenser, citado por Root Bernstein (2000), afirma en relación con la creación poética que, "por encima de cualquier otra cosa, el poeta es una persona que nunca olvida ciertas sensaciones-impresiones que ha experimentado y que puede revivir una y otra vez con toda su frescura original..." (23).

Encontramos en la siguiente estrofa esas sensaciones-impresiones, cuando la canción poema dice: "Entonces fue que fui/ de nuevo un güila, correteando/ en los potreros,/ loco y descamisado me perdí/ en el verano de caminos polvorientos..."

La palabra güila marca una diferencia, remite a lo costarricense, al campo, a los abuelos; provoca sentimiento, emociones, recuerdos, imágenes, identidad e identificación: "descamisado/ caminos polvorientos" refuerza las sensaciones de la niñez, de libertad, de una Costa Rica añorada por muchos.

Recordemos que las migraciones campo-ciudad son relevantes en la transformación demográfica costarricense, y que aunque ha sido un fenómeno histórico para América Latina, este se incrementa en ciertas épocas y de acuerdo con estímulos como trabajo y estudio. Costa Rica; no es la excepción, y según el historiador costarricense Guillermo Carvajal (1985), los años de mayor concentración de población en la subregión metropolitana costarricense se dan entre 1968 y 1973 :

En el período intercensal 1968-73, la tasa de crecimiento demográfica fue del orden de 4,10\%, muy superior a la experimentada por el país en su conjunto. Entre estos dos censos se produjo un fuerte aumento de la población de esta área. Este aumento de la población es producto de múltiples factores, entre los que se destacan las altas tasas de crecimiento vegetativo combinadas con una afluencia cada vez más importante de población proveniente de las restantes regiones del país. (259)

Podemos entonces encontrar un primer esbozo de respuesta al porqué de la filiación identitaria de los y las costarricenses con Malpaís, y es esa añoranza por lo ancestral y con la Costa Rica de los abuelos y abuelas de estas generaciones o incluso la de sus propios padres, o sencillamente con sus raíces, en una relación empática de identificación. 
Expresiones como la que se repite constantemente en la canción-poema Presagio, /Huele a agua/, acompañadas de imágenes como: /monte adentro/ y en el cielo braman/tambores de trueno/.../Decía mi abuelo, /garrotes de agua/ golpean los cerros/.../Y el viento se ha vuelto negro/ y sabe a miedo/ y allá vuelan zopilotes/en torbellino sobre los techos/. Son todas expresiones reconocidas y reconocibles para los y las costarricenses y para todas aquellas personas que han tenido una relación intrínseca con la lluvia.

El yo de la voz se expresa en los versos iniciales de la canción-poema como un observador, un contador de lo dicho, de la experiencia del abuelo, transmisión del conocimiento de una generación a otra. Otro elemento de identificación de lo costarricense, se da con la lectura de signos naturales relacionados con los cambios de estaciones, con la siembra, con nuestro rizoma generacional campesino.

En un segundo momento y dentro de la misma canción-poema, no encontramos con que:

...Y el tiempo es un agujero

y sabe a pólvora,

se retuerce en el pellejo

de la desgracia la mala hora...

Con el tiempo es un agujero/sabe a pólvora/se retuerce y llega la mala hora, hay un presagio, la llegada de la mala hora, cargada de signos de desesperanza por parte de la voz que se expresa, y casi de inmediato una advertencia de lo que acontece:

Huele a agua en el desierto

y a lo lejos...

Están los grandes animales

rompiendo la selva

tragándose los árboles.

Son los "garrobos llamarada",

mariposas negras

en el aire.

Todos los acontecimientos están en tiempo presente, grandes animales rompen la selva, se tragan los árboles, la voz los llama o identifica como "garrobos llamarada" (los garrobos son saurios que abundan en tierras cálidas y en las costas) y /mariposas negras en el aire/ a manera de un presagio, que a la vez es el título de la canción.

Debemos detenernos aquí en tres detalles del discurso poético: el primero es que se rompe la armonía de la normalidad de los eventos naturales como la presencia de grandes aguaceros en la montaña con la intromisión del sustantivo pólvora que implica presencia humana; el segundo, grandes animales que rompen la selva y se tragan los árboles, "garrobos llamarada" les dice la voz para describir los /grandes animales.../, puede inferirse que se refiere a maquinaria 
pesada, que como los garrobos parecen saurios y llamarada por el color amarillo predominante en ese tipo de máquinas; y lo tercero, la presencia de mariposas negras en el aire, sabemos que la mariposa simboliza el cambio, la transformación (metamorfosis), pero estas son negras. En Occidente, lo negro se relaciona con el luto, lo triste, la muerte; es decir, lo que viene no es bueno; también en lo popular supersticioso costarricense las mariposas negras no son buen augurio, de ahí el presagio.

La voz interpreta y advierte: Cuidao [sic] mama [sic], que allá vienen las bestias, / Cuidao mama, que vienen en manada, /las fieras terribles y hambrientas están aquí. / Se acercan levantando polvo en el llano...

El lenguaje es campesino coloquial costarricense, cuidao en vez de cuidado y mama en vez de mamá, quien muchas veces es la abuela; también recuerda nuestras raíces campesinas o cercanas a la tierra, un pasado que se va y un lenguaje campesino aún fácil de comprender y de filiación identitaria.

La siguiente estrofa parece referirse a la burla de quienes observan o escuchan la advertencia, los de las /máscaras/: "Y en la calle rondan máscaras/ de carcajada,/ me persiguen cinco muecas/ y soy preso de una fábula”.

Según Juan Eduardo Cirlot (1994), la máscara involucra la transformación; para él lo equívoco y lo ambiguo se producen en el momento en que algo se modifica lo bastante para ser ya "otra cosa" pero aún sigue siendo lo que era (299), por lo que esos cambios o metamorfosis tienen que ocultarse, por ello el uso de la máscara, y peor aún, /máscaras de carcajada, / lo que parece implicar la burla hacia la voz presagiante, quien además es perseguido por /cinco muecas/y es /preso de una fábula/; en la fábula clásica siempre vamos a encontrar una oposición entre dos personajes en desigualdad social, favorable para uno, desfavorable para el otro.

A pesar de todo, y del presagio/Ha llovido, pero siempre en la distancia/huele a agua..., no se borra la esperanza, el agua, además de otras cosas, es símbolo del origen de la vida y la regeneración, origen y vehículo de toda la vida, llovida es don del cielo, fertilidad (Chevalier, 1986: 270).

La canción-poema describe y evoca situaciones conocidas por los y las costarricenses, quienes comprenden los signos que la voz lírica expresa y se identifican con ellos, con la invasión de tierras vendidas a extranjeros y a grandes consorcios hoteleros, que cambiaron los paisajes para siempre, la privatización de las playas, y la lucha de unos cuantos por cuidar la tierra costarricense, y las nacientes de agua. Una gota de agua, una gota de agua, así se inicia la canciónpoema en los conciertos de Malpaís.

Los textos de las coanciones contienen ritmo, entonación, música y tantos otros elementos que acompañan los poemas-canción, lo que les imprime mucha más fuerza y poder de identificación para quienes escuchan y reproducen las letras mientras el grupo las interpreta.

Esa identificación de los y las costarricense es definida por Fidel Gamboa Goldemberg así:

la identificación de la gente con Malpaís..., es que no sé en qué lugar del corazón la estamos tocando así; porque posiblemente estamos hablando 
de cosas que les son comunes: todo el mundo tiene una abuela, se acuerda de cómo eran esas cosas; a nivel visual la foto del primer disco es una foto que seguramente tienen todas las familias en algún álbum viejo: la muchacha curvilínea a la par de un Ford viejo..., o la foto de la señoras con los chiquitos jugando en el patio... Estamos hablando de cosas que a los costarricenses les son comunes (La Nación, 2006).

Volóshinov (2009), del círculo de Bajtín, se refería a la enunciación como el suceso histórico y sublime que relaciona dos sujetos y que se explica a partir del contexto social al cual pertenecen, y que incluso si no existiera un interlocutor real, este podría ser sustituido por el representante medio del grupo social al que pertenece el locutor, es decir, quien enuncia. Además, los enunciados implican la intencionalidad del locutor frente a su interlocutor y al tener la enunciación un carácter social se convierte en inseparable de las relaciones ideológicas. La palabra, entonces, se ubica en un contexto social e histórico ya determinado.

Cuando Malpais enuncia, cuando su voz es escuchada, los interlocutores se identifican, corean sus canciones-poemas, gritan, acompañan y algunas veces lloran, se encuentran allí, inmersos en esas historias, en esos contextos, no son ajenos a la realidad que se expresa, cada signo se transforma en símbolo de una identidad tan diluida en el fenómeno globalizante y globalizador, pero que nos abofetea en la cara: "Regresar con los ojos desconocidos,/ Desempolvando besos y nostalgia./ Regresar cuando todo sabe a recuerdo,.../". Las palabras tienen una carga ideológica y como tales forman parte de un sistema mayor; el lenguaje (Volóshinov, 2009: 35), la conciencia individual es un hecho ideológico y social.

No existe un solo signo cultural que, al ser comprendido y conceptualizado, quede aislado, sino que al contrario, todos forman parte de la unidad de una conciencia estructurada verbalmente (Volóshinov, 2009: 39), y Malpaís, su discurso poético e identitario se unen como una cadena de significantes y significados culturales en los que los y las costarricenses se encuentran una y otra vez.

Es mucho lo que se podría decir, analizar o estudiar de este grupo musical y sus textos-poemas, o incluso de su musicalización, utilización de instrumentos, improvisación, ritmos y otros. Nosotros solo nos acercamos desde una perspectiva y con un solo enfoque que nos permitió comprobar que Malpaís es un fenómeno o asidero identitario para los y las costarricenses y que su música no tiene edad ni límites espacio/temporales, y que sus textos son mucho más que solo canciones, son también poemas. Concluimos con estas estrofas de Muchacha y luna:

... Y regresar cantando y enamorado

En la cálida magia de una caricia

Mi Nicoya dormida en el aguacero...

Allí donde se levantan los hijos de la siembra

Revientan en el aire, todas las estrellas, donde la tierra agreste se mezcla con la sangre, e inevitablemente mi corazón se vuelve pájaro...Llanura... 
Arena y Espuma...

En la noche te haré el amor bajo los árboles, muchacha y luna...

Regresaré con prisas en la garganta

A recorrer distinto las mismas calles,

las mismas avenidas y ventanas,

las soledades...

Y buscaré tu cuerpo, agua del río, perdido entre la sombra de estos bosques cristalino y oscuro y amanecido...

\section{Bibliografía}

Alvar, Manuel. Símbolos y mitos. Madrid: C.S.I.C., 1990.

Bohm, David. 2001. Sobre la creatividad. Barcelona: Kairós, 2001.

Carvajal Alvarado, Guillermo. 1985. "Migraciones internas en Costa Rica: una aproximación regional al problema”. Revista Geográfica de América Central, Vol 2, No 17-18, 1985, pp. 239, 273.

Cirlot, Juan-Eduardo. Diccionario de símbolos. $3^{\mathrm{a}}$ ed. Barcelona: Editorial Labor, 1994.

Chevalier, Jean. Diccionario de los símbolos. Barcelona: Editorial Herder, 1986.

Grupo Malpaís. s.f. En: www.grupomalpais.com. Fecha de acceso: enero-febrero del 2014.

Lacan, Jacques. El seminario16. De un Otro al otro (1968-69). Buenos Aires: Paidós Ibérica, 2008.

Lara, Gladys. "Bolero: el amor, el texto y la cultura. Enunciación”. Disponible en: http://revistas.udistrital.edu.co/ojs/index.php/enunc/article/view/2535/3565. [S.1.], v. 4, n. 1, 2004, p. 82-88. Fecha de acceso: 23 ene. 2014.

Lotman, Iouri M. 2003. "El símbolo en el sistema de la cultura". Entretextos, Revista electrónica semestral de Estudios Semióticos de la cultura. 2003. Disponible en: http://www.ugr.es/ mcaceres/entretextos/pdf/entre2/escritos/ escritos4.pdf. Fecha de acceso: 26 de febrero del 2014.

Lotman, Iouri M. La estructura del texto artístico. Madrid: Istmo, 1978.

Root-Bernstein, Robert y Michelle. El secreto de la creatividad. Barcelona: Kairós, 2000.

Volóshinov, Nicolás. El marxismo y la filosofía del lenguaje. Trad. Tatiana Budnova. Buenos Aires: Godot, 2009. 
